\title{
THE TOYOTA PRODUCTION SYSTEM - CZECH AND NIPPON CULTURAL PERSPECTIVES
}

\author{
Richard Brunet-Thornton, Michal Koža, Vladimír Bureš
}

\section{Introduction}

Japanese companies are considered a benchmark from various perspectives in the realm of business and management. Their foreign direct investments (FDI) have been considerable over the last decades in Central Europe. Multinational Enterprises (MNEs) are by their nature prone to cross-cultural interaction (Rozkwitalska, 2010). This is especially significant in the case of Japanese MNEs, which heavily rely on the use of expatriates to control foreign subsidiaries and implement foreign managerial systems (Harzing, 1999). Outside of Japan, host country employees in many Japanese subsidiaries interact with Japanese expatriates and management relocation activities on a daily basis. Such cross-cultural interaction often creates interpersonal friction, conflicts and other problems. In the global context, these conflicts between local employees and expatriates in subsidiaries are relevant, as they may impair the efficiency of the entire organisation (Pudelko \& Tenzer, 2011). Although studies focused on comparison of European and Asian cultures have already been published recently, for instance Li et al. (2016) deals with the United Kingdom and China, or Linder (2015) investigates German expatriates in Philippines, recent comparison of a Central European country with Japan is missing in the literature.

One approach to explain and analyse these conflicts and the success of managerial systems is the application of the cultural differences concept (Ayoko, Härtel, \& Callan, 2002; Vaara, 2003). Another stream of literature deals with the problem from a Human Resources Management perspective (Pudelko, 2000). To resolve expatriation-specific complications, both approaches stress the importance of crosscultural awareness training programmes and overall support and assistance to expatriates
(Pudelko \& Tenzer, 2011). This awareness and support is often vaguely defined and lacks analysis. Even though both approaches analyse the degree of acceptance of various tools, they focus only on the tools. Less attention is paid to a wider perspective that possibly serves as a definitive framework for these tools.

This discussion analyses the effect of Czech managers' cultural values on the acceptance of the Toyota Production System (TPS), a Japanese manufacturing and managerial framework and philosophy (Liker, 2004) shared by most automotive Japanese subsidiaries in the Czech Republic and elsewhere. It also examines the situation relative to the satisfaction and degree of conflict in Japanese MNEs in the Czech Republic from both Czech and Japanese viewpoints. In doing so, it determines the outcome of Czech and Japanese employees' knowledge and appreciation of the Toyota Production System on corporate performance. Equally, it analyses the amount and severity of conflicts between local and expatriate managers. Moreover, it addresses the insufficient research on performance in Japanese MNEs in a specific environment as there exists little literature that reviews job-satisfaction, conflict, and TPS training in the Czech Republic as a culturally specific environment (Brunet-Thornton \& Bureš, 2012).

\section{Theoretical Background}

This section presents general frameworks developed in the area of cross-cultural management and highlights those applied in this study. Consequently, the main ideas and principles of the TPS are introduced.

\subsection{Cross-Cultural Frameworks}

Hall (1959) introduced three basic components to comprehend various aspects of cultures: 
monochronic and polychronic time orientation, proxemics and high context and low context culture. Monochronic describes a culture, which tends to do one thing at a time sequentially. They plan and schedule. In contrast, polychronic cultures do things simultaneously, and are focused on an individual perception of time. Regarding space, Hall divided this dimension into four distances: intimate, personal, social and public. Various cultures perceive space differently, and what one culture perceives as intimate may be viewed as social space in a different culture.

The Hampden-Turner and Trompennars (1998) model compares cultures through seven bipolar dimensions: Universalism/Particularism, Individualism/Collectivism, Neutral/Affective, Diffuse/Specific, Achievement/Ascription, Attitude to Time, and Attitude to the Environment.

The Hofstede (1983) Cultural Dimensions model, based on a series of surveys conducted on IBM employees originally identified four dimensions of national cultures: Power Distance, Uncertainty Avoidance, Individualism, and Masculinity-Femininity. In later research, two additional values have been added to this group: Long-Term vs. Short-Term Orientation and Indulgence/Restraint. Although often criticised the Hofstede model is frequently cited (BrunetThornton \& Bureš, 2012). Research (Bergiel, Bergiel, \& Upson, 2012; Kohun, Burčik, \& Skovira, 2012) indicates that the values evolve and therefore do not represent constants for the accurate calculation of the dimensions thereby, rendering comparisons difficult.

Based on the Hofstede model, Kogut and Singh (1988) developed the concept of cultural distance to express cultural differences and characteristics on the choice of market entry in foreign direct investments. The concept of cultural distance has been used in various other studies such as, the measurement of the efficiency of managerial networks (Manev \& Stevenson, 2001), knowledge transfer (Holtbrügge \& Berg, 2004), internalisation processes of firms (Clark \& Pugh, 2001), MNE performance (Gómez-mejia \& Palich, 1997), as well as to gauge the level of conflict between Japanese and western companies (Pudelko \& Tenzer, 2011). The larger the cultural distance between two countries suggests the possibility of conflicts between two nations within one entity, as in the case of a Japanese subsidiary in the Czech Republic. Although there currently exist a number of methodologies (Yeganeh, 2011; Gerschewski, 2013). This study utilises the Yavneh's (2011) formula. It accounts for cultural asymmetry, both negative and positive values; dimensions' alignment, does not aggregate opposing cultural dimensions, and weight, cultural dimensions have unequal importance, thus relative weights are factored.

Yeganeh's cultural distance formula for the Hofstede dimensions

$$
\begin{aligned}
& C D_{a b}=\left\{-0.1 \frac{\left(P D_{a}-P D_{b}\right)}{s d_{P D}}+\right. \\
& +0.79 \frac{\left(I N_{a}-I N_{b}\right)}{s d_{I N}}-0.09 \frac{\left(M A_{a}-M A_{b}\right)}{s d_{M A}}+ \\
& \left.+0.01 \frac{\left(U A_{a}-U A_{b}\right)}{s d_{U A}}\right\}
\end{aligned}
$$

where $C D_{a b}$ represents the cultural distance between countries $a$ and $b$, variables $\mathrm{PD}_{\mathrm{a}}, \mathrm{PD}_{\mathrm{b}}$ ... UA $\mathrm{A}_{a}, \mathrm{UA}_{b}$ represent the Hofstede cultural dimensions for each respective country.

The cultural distance between the Czech Republic and Japan based on Yegahen's (2011) formula and using a dataset acquired from Harzing (2014) is -67.37. Kogut and Singh's distance index is 0.9 . Figure 1 compares these results with other countries. Kogut and Singh's distance index, $X$ distance, indicates that the distance between the Czech Republic and Japan resembles the cultural distances between the Czech Republic and Hungary, Russia, USA, and Austria. The Yeganeh's index, $Y$ distance, demonstrates that other countries with a similar distance to the Czech Republic as Japan are Poland, Russia and Spain. However, Italy, German, and France are countries with a relatively small cultural distance. The correlation between the Kogut and Singh's formula and absolute values of Yeganeh's formulae is $83.8 \%$. The lines in the graph illustrate a theoretical $100 \%$ correlation between Yeganeh's and Kogut and Singh's formulae.

\subsection{Toyota Production System}

The TPS was originally created by a group of engineers in the 1950s as a set of manufacturing principles and tools for the Toyota Motor Company. It was developed as a system based on employee implicit know-how and common 


\section{Fig. 1: Plotted cultural distances}

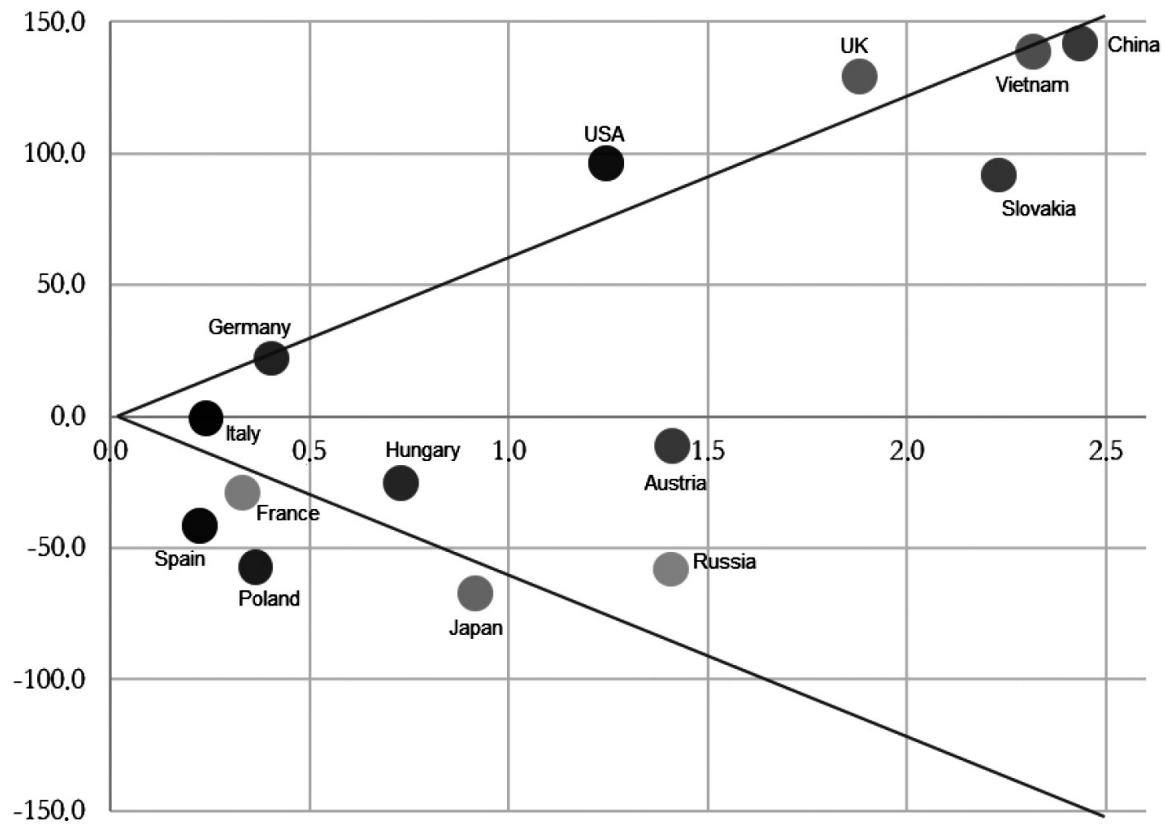

Source: own

knowledge. The rules are based on the premise to share tacit values within the group. Thus, to understand the TPS, acknowledgement of the cultural context within the organisation, and especially the working group is crucial. From the manufacturing position, the system uses various common within production environments, such as Total Quality Management (Liker, Fruin, \& Adler, 1999), Kanban-based pull production, 5S, Just-in-time production, and others. Ultimately, its main purpose is "to eliminate through improvement activities various kinds of waste lying concealed within a company" (Monden, 2013). By themselves the tools do not create the TPS backbone but are just one part of the whole system. After studying more than 40 Toyota factories in the USA, Europe and Japan, Spear and Bowen (1999, p. 98) define these four rules:

1. How People Work - All work should be specified as to content, sequence, timing and outcome.
2. How People Connect - Every customersupplier connection must be direct, and there must be an unambiguous method to transmit requests and receive responses.

3. How the Production Line is Constructed The pathway for every product and service must be simple and direct.

4. How to Improve - Any improvement must be made in accordance with the scientific method, under the guidance of a teacher, at the lowest possible level in the organisation.

These four rules provide a foundation to create, organise, and view work. When compared with other tools, these rules highlight that true implementation of these ideas is impossible without a thorough process aimed at both the horizontal and vertical structures of the enterprise.

Originally a set of techniques and tools, TPS gradually developed into a deeper philosophy known as The Toyota Way (Liker, 
2004). Today, it is a system of manufacturing as well as management principles used in various industries that include manufacturing or medicine. Liker (2004) views the philosophy as a concept that consists of four main components: Philosophy (Long-Term Thinking), Process (Eliminate Waste), People and Partners (Respect, Challenge and Grow Them), and Problem Solving (Continuous Improvement and Learning).

The Toyota Way (TW) is shaped by two basic pillars: Continuous improvement and Respect for people. In turn, these two value groups encompass five key principles: Challenge, Kaizen (improvement), Genchi Genbutsu (go and see), Respect and Teamwork (Toyota, 2003). Studies reveal that when empirically measured, these five principles are not statistically different from each other, as they are highly inter-correlated a to the measurement system used by Toyota to measure the TW (Jayamaha, Wagner, Grigg, Campbell-Allen, \& Harvie, 2014, p. 2).

Liker (2004) presents 14 principles that constitute the TW. His perception is based on the 4-pillar model. The principles summarised are as follows:

1. Base your management decisions on a long-term philosophy, even at the expense of short-term financial goals.

2. Create a continuous process flow to bring problems to the surface.

3. Use 'pull' systems to avoid overproduction.

4. Level out the workload (work like the tortoise, not the hare).

5. Build a culture of stopping to fix problems, to obtain quality the first time.

6. Standardised tasks and processes are the foundation for continuous improvement and employee empowerment.

7. Use visual controls so no problems are hidden.

8. Use only reliable, thoroughly tested technology that serves your people and process.

9. Grow leaders who thoroughly understand the work, live the philosophy, and teach it to others.

10. Develop exceptional people and teams who follow your company's philosophy.

11. Respect your extended network of partners and suppliers by challenging them and helping them improve.

12. Go and see for yourself to thoroughly understand the situation.

13. Make decisions slowly by consensus, thoroughly considering all options; implement decisions rapidly.

14. Become a learning organisation through relentless reflection and continuous improvement.

\section{Problem Formulation}

The increased number of Japanese subsidiaries in the Czech Republic indicates the importance of these companies to the Czech economy. Their performance is based not only on a macro-environment and international strategy of the organisation, but on the efficiency of local operations. Thus, it is crucial to analyse methods to mitigate possible friction and to improve management efficacy. The authors focus on two main problem areas.

The first consideration is the cultural fit of values within the Toyota Production System and the cultural values of Czech managers responsible for the implementation of these management and manufacturing techniques together with the Japanese expatriates. The TPS is often used as a synonym for "lean production" (Fujimoto, 1999) and many companies understand it as a process to improve performance. There exist Toyota Institutes in the USA and Thailand, wherein the rules and values of the TW are taught in explicit fashion. Such venues do exist in the Czech environment. Therefore, the first set of questions this study addresses is:

- Prior to implementation, without welldefined TPS training, does a natural fit of values inherent to Czech managers and values exist?

- Without sufficient training, is TPS applicable within a Czech work environment?

The second area of research is the question of usability of the TPS knowledge in terms of performance improvement. Research identifies basic approaches to improve the overall performance of cross-cultural management: cultural awareness, intercultural effectiveness, experimental or cognitive cross-cultural training and language-management. The cross-cultural training does not automatically provide successful outcomes. It is often concluded within an insufficient time-frame, or in an inadequate manner. The requirement for a successful language-management strategy 
is a long-term oriented effort. In the case of Japanese companies with a large ratio of Japanese-only speakers, this effort is ignored, and in most cases, the official working language is Japanese (Harzing \& Pudelko, 2013).

TPS could potentially combine these two approaches, and serve as a "common language" for both sides within a cross-cultural conflict. In doing so, thus foster cross-cultural awareness, smoothen daily operations and establish a basic platform for communication, problem solving and the setting of priorities. On one side of the cross-cultural conflict is the local managers' position. The local manager becomes frustrated due to the centralised decision-making and lack of understanding. The other side of the conflict consists of the Japanese expatriates, who struggle to express the reasons for the behaviour often citing cultural or language differences. Thus, the second research question:

- Do the rules and principles of TPS provide a basic platform for comprehension between two cultures, and therefore improve the satisfaction of employees and lower the amount of conflicts?

Subsequently, three working hypotheses are tested:

H1. Values inherent to Japanese management are closer to the values proposed by the TPS than the values inherent to Czech management.

H2. If a company has Czech management trained in the area of TPS, the company enjoys a lesser degree of conflict between Czech and Japanese management.

H3. If a company has Czech management trained in the area of TPS, the company realises a higher level of Czech employee job satisfaction.

\section{Methodology}

The presented study is intended to be in concordance with other cross-cultural studies. Therefore, instead of plain analytical statistical data processing that would not guarantee conformity in the given field of study, wellestablished cross-cultural metrics and approaches are applied. Thus, the presented study represents a mixed research approach that takes advantage of both quantitative and qualitative aspects of a research design. The hypotheses are tested using survey data. The main questions are constructed to describe the respondents' values relative to the TPS pillars and principles. A copy is found in the Appendix. TW pillars and Liker's 14 principles are then compared and analysed. Out of Liker's 14 principles, six are identified as technical: 2 , $3,4,5,7$ and 12 . They have not been taken into account during the creation of the survey. Two principles are categorised as corporate strategy: 11 and 14 . The remaining six principles are merged together with observations from Spear and Bowen (1999). As a result, five different values are identified as Long-term orientation in thinking; Innovation perception; Human Resources development; Respect for rules; and Respect for supervisors.

The self-assisted questionnaire (SAQ) consists of 19 short questions related to cultural values and nine specific to the respondent. To quantify the respondent's values, semantic differential scales, 5-scale Likert scales and single numeric value fields are used. Recent research demonstrates that various types of scales produce different results (Friborg, Martinussen, \& Rosenvinge, 2006). Except for the name of the company, position and comments, optional fields used only for statistical purposes, none other qualitative data is collected. All questions used in the SAQs are built in three languages, English, Czech, and Japanese. Accidental sampling and snowball sampling methods are the primary techniques.

Prior to distribution, which took place in the mid of 2014, a pilot-run was conducted. One company with five Czech and five Japanese managers was contacted with the SAQ distributed through the Human Resources department. Following the trial, no major changes were required to the questionnaire. The survey was distributed using three separate channels scanned files sent and collected through email; online survey through a specialised platform; and physical distribution of printed surveys. Email recipients were informed on the survey purpose and provided with two URL links, one to the Czech and one to the Japanese versions.

Although distribution represented seventynine enterprise contacts, more than one third of respondents, $35 \%, n=45$, did not reveal their corporate name. A distribution list is included in the appendix. The survey targeted both Czech and Japanese managers, which includes, plant, quality, production process, maintenance and 
improvement managers. Out of one hundred twenty-nine responses, 108 were relevant, a reply rate of $82.9 \%$. Altogether, 45 responses were received from Czech managers and 63 responses from their Japanese counterparts. Seniority within the enterprise presents 7.2 years for Czech respondents and 5.8 years for the Japanese.

\section{Results}

\subsection{Value-Related Questions}

Data collected associated with the ten relevant questions were summarised with averages for each respective value calculated. Figure 2 indicates the difference of each nationality between its average value and the middle value used in the 5-point Likert scales and the 5-point semantic differential scales. The $x$-axis displays the number of questions that measure the respondents' values: section 1 with questions $1-6$ and section two with questions $7-10$. The left $y$-axis indicates the average values for respective question and nation with dark grey for Czech and light grey for Japanese.

This illustration displays the difference between the two groups. Questions 1, 2, 5, 7, 8 , and 9 deviate most from the medium value. Questions 3, 4, 6, and 10 are the closest to the medium. The largest differences are with questions 1, 2, 3, 5, 6, 7, and 10. Questions

\section{Fig. 2: Differences between average and middle values}

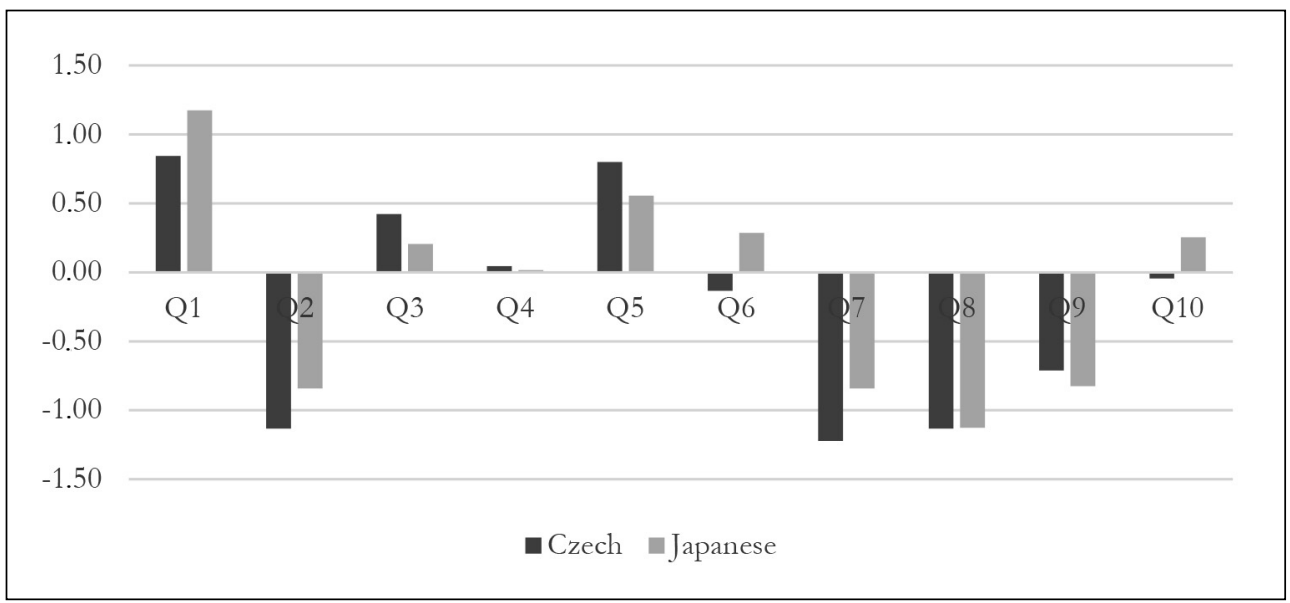

Source: own

one through six are semantic differential scales, questions seven through ten are 5-point Likert scales.

\subsection{Satisfaction-Related Results}

Both groups are satisfied with the number of work-hours. The overall difference is $d=0.29$. Although Czech companies have a standard 8-hour long work day, many Japanese workers remain at work longer. Official statistics state that the average annual work-time in Japan is 1,785 hours, which is lower than the Czech (OECD, 2014). This indicator however, considers parttime workers that includes $24.5 \%$ in 2006 , more than seven times that of the Czech Republic.
It is therefore, difficult to use this absolute number for comparison. According to Fukuda (2012), 28\% of Japanese employees work more than fifty hours per week. This renders Japan in second place preceded by South Korea (45\%). The reason for this behaviour is more complicated than conscientiousness. Marsden (1999, p. 165-166) proposes that this behaviour reflects the stress on quality, job rotation and skill development.

Both cultural groups express satisfaction with the monetary reward $(d=0.42)$. Compared with the number of work-hours, Czech managers appear more satisfied with their salaries. Japanese managers indicate the 
same level of satisfaction as in the previous question. Although compensation strategies differ by company, Japanese expats receive on average a remuneration package that consists of various bonuses equal to 2.8 times the salary of host country employees at the same grade and position (Wong \& Hendry, 1999).

There is dissatisfaction with training and education. The result is most notable with Japanese managers, with a mean value of 3.02 , 0.55 higher than their Czech counterparts. The role of Japanese expats in foreign countries is often two-fold (Delios \& Bjorkman, 2000). The primary role is to control the activities of the subsidiary to align with the goals of head office. The second is to function as a knowledge base for local employees. Serving as a knowledge source lowers the number of opportunities for further formal expat education. As a result, they find themselves unprepared for new challenges when abroad.

Overall, the level of satisfaction of Czech managers is higher. This does not necessarily signify that Japanese workers are less satisfied in foreign assignments than at home. Though it is most likely possible that the workload, interpersonal relationships and overall working conditions in foreign countries are more demanding, the survey did not explore the possible differences between Czech and Japanese environments. Nevertheless, what may be concluded is that the perception of working conditions between the two groups is different.

\subsection{Conflicts-Related Results}

Questions were constructed with a 5-point Likert scale within a range of 1 for "absolutely true" and 5 for "absolutely not true". The first question measures the number of conflicts between the respondent and the management of the other culture. The difference between the two groups is large $(d=1.34)$.

The second question measures the same issues as the previous but with one difference. It enquires as to the general state of relations between Japanese and Czech management. The findings indicate that Czech managers estimate the tensions between the two groups to be larger than in-group conflicts $(d=1.06)$.

The third question measures the difference in conflict perception. Japanese managers perceive the degree of conflicts between them and the Czech operators to be greater than the Czech perception $(d=1.24)$.

One of the many definitions of culture describes it as "the method of solving problems" (Schein, 1985). According to the results of the fourth question, Japanese managers view problem resolution with the other culture as more effective, than their Czech colleagues $(d=0.68)$.

\subsection{Testing of Hypotheses}

H1: Values inherent to Japanese management are closer to the values proposed by the TPS than the values inherent to Czech management.

Out of the ten questions that measure values identified as relative to TPS, four were identified in contradiction of expectations. This suggests that Czech managers exhibited characteristics closer to values expected of Japanese managers. Four questions met expectations, and two questions produced unanimous results. Table 1 summarises the differences for each measured variable, and results for questions connected with these variables. Thus, the hypothesis $\mathrm{H} 1$ is refuted.

A positive integer indicates that the difference is in accordance with expectations. A negative, that the difference contradicts expectations. Zero indicates that the difference

\section{Tab. 1: Overview of measured values and variables}

\begin{tabular}{l|c|c|c} 
& First question & Second question & Sum \\
\hline Long term & -0.38 & 0.29 & -0.09 \\
\hline Innovation perception & 0.30 & -0.33 & -0.03 \\
\hline Supervisor respect & -0.42 & 0.22 & -0.20 \\
\hline HR development & -0.24 & 0.00 & -0.24 \\
\hline Rules respect & 0.11 & 0.00 & 0.11 \\
\hline
\end{tabular}


is insignificant. The sum for four out of the five variables is negative as well as the total sum of all variables $(-0.45)$. This does not necessarily suggest that the hypothesis is unambiguously denied. To do so, the variables would need respective weighting based on multiple observations in multiple environments. The actual relevance of these variables to TPS is unknown as no other quantifying research has been conducted. Hence it is impossible to clearly answer this issue. Nonetheless, for each measured variable, there exist contradictions.

H2: If the company supports TPS training of Czech management, the company enjoys a lesser degree of conflict between Czech and Japanese management.

To assess the second hypothesis, TPSrelated training for each employee is divided into three groups. Group " 0 " consists of employees that did not receive any formal or informal training. Employees in group "1" have noted that they received some training. To measure the degree of conflict, results for the first conflict-related question were used: there exist many conflicts between you and management of other than your own nation. Findings are found in table 2.

As the table indicates, there exists minimal difference in the amount of conflict between Czech managers with or without formal TPS training (0.11). The difference between Czech managers with or without informal training is larger $(0.27)$. In the case of Japanese managers, the differences are 0.29 for formal training and 0.44 for informal training. Thus, the hypothesis $\mathrm{H} 2$ is refuted.

It appears that with increased training, the degree of conflict rises, the lower the number, the higher the perception of conflict.

\section{Tab. 2: Average conflicts divided by level of TPS training}

\begin{tabular}{c|c|c|c|c|c|c|c|c} 
& \multicolumn{4}{|c|}{ Official TPS training } & \multicolumn{4}{c}{ Non-official TPS training } \\
\hline $\begin{array}{c}\text { Level } \\
\text { of training }\end{array}$ & Czech & (n) & Japanese & (n) & Czech & (n) & Japanese & (n) \\
\hline $\mathbf{0}$ & 4.03 & 32 & 2.76 & 46 & 4.18 & 17 & 2.86 & 37 \\
\hline $\mathbf{1}$ & 3.92 & 13 & 2.47 & 17 & 3.89 & 28 & 2.42 & 26 \\
\hline
\end{tabular}

\begin{tabular}{c|c|c|c|c} 
& \multicolumn{2}{|c|}{ Formal TPS training } & \multicolumn{2}{c}{ Informal TPS training } \\
\hline Work hours & Czech & Japanese & Czech & Japanese \\
\hline $\mathbf{0}$ & 2.22 & 2.78 & 2.06 & 2.59 \\
\hline $\mathbf{1}$ & 2.69 & 2.29 & 2.54 & 2.73 \\
\hline Training & Czech & Japanese & Czech & Japanese \\
\hline $\mathbf{0}$ & 2.22 & 2.76 & 2.41 & 2.68 \\
\hline $\mathbf{1}$ & 2.23 & 2.35 & 2.11 & 2.62 \\
\hline Salary & Czech & Japanese & Czech & Japanese \\
\hline $\mathbf{0}$ & 2.66 & 3.11 & 2.71 & 2.95 \\
\hline $\mathbf{1}$ & 2.00 & 2.76 & 2.32 & 3.12 \\
\hline Overall & Czech & Japanese & Czech & Japanese \\
\hline $\mathbf{0}$ & 2.13 & 2.50 & 2.24 & 2.35 \\
\hline $\mathbf{1}$ & 2.08 & 2.29 & 2.04 & 2.58 \\
\hline
\end{tabular}


H3: If a company promotes Czech management training on the TPS, the company realises a higher level of Czech management job satisfaction.

Hypothesis $\mathrm{H} 3$ was assessed in a similar manner as hypothesis H2. First, two groups for the TPS-related training were identified with "0" for no training and " 1 " for at least some training. Based on these groups, satisfaction for all four sub-questions was averaged separately: Work hours, Salary, Training and Overall Satisfaction. A lower number signifies higher satisfaction and vice versa. Results are summarised in table 3 .

Czech managers with formal or informal TPS training display lower satisfaction with the length of work hours. Formal TPS training does not appear to have any impact on the level of satisfaction related to training. However, Czech managers who experienced informal TPS rate higher satisfaction levels. Managers with both formal and informal training indicate a higher satisfaction with salary. Overall satisfaction levels for Czech managers specify a weak positive correlation in that managers with any type of training are more satisfied than managers without. Nevertheless, the hypothesis $\mathrm{H} 3$ is refuted.

Although Japanese managers exhibit similar trends within the satisfaction subgroups, the results are different. For example, Japanese employees with formal training indicate higher satisfaction with work hours. Japanese employees with informal training demonstrate an opposite trend. Formal training associates with higher satisfaction levels with training, salary, and inclusive approval. On the other hand, employees with informal training exhibit an indifference to training satisfaction, as well as a lower satisfaction in both salary and overall contentment.

\section{Discussion}

\subsection{Values}

Results of question 1 reveal a difference between the two groups ( $d=0.33)$. In addition, the values contradict the expectations set by the literature review. According to Hofstede (2010), Japan's higher uncertainty index, 92 compared with 74 for the Czech Republic, implies that Japanese managers have a tendency to avoid risk and prefer to utilise well-established methods and technologies. It is feasible that Japanese managers see the importance of new technology as something more crucial in the context of foreign subsidiaries as a means to improve structure and rules within an organisation (Cardon \& Marshall, 2008).

The results for the second question are consistent with the literature review (Liker, 2004). The Czech managers' average is 1.87 ; Japanese managers' average is 2.17 , thus higher by 0.31 , and therefore more inclined towards the second statement. In the instance that a process does not produce the expected results, Czech respondents tend to innovate to modify the process and adjust the parameters. Alternatively, their Japanese counterparts deploy known solutions under the premise that changes require time to take effect.

Czech managers score higher values than the Japanese respondents $(d=0.23)$, that in turn signifies that the responsibility of possible misunderstandings resides with the supervisor. This result confirms previous research that the Japanese form a society with strong vertical connections. In the work environment, superiors are viewed as mentors (senpai), who paternalistically care for the younger inexperienced employee (Lincoln, Kerbo, \& Wittenhagen, 1995, p. 428).

Responses associated with the fourth question account for a difference less than 0.03 points. However, the variance for this question was the highest among all value-related questions with 1.35 compared to an average variance of 0.93 . Goal-setting depends on the employee's position and subsequently differs for a manual worker and a manager. Therefore, expectations are related to the role and level of responsibilities necessitated by the actual job.

With respect to the fifth question, Czech managers score higher than their Japanese counterparts, 3.80 to 3.56 respectively. It indicates that it is more important to hire and develop managers from internal resources than external. This finding contradicts expectations. Contrary to the Czech Republic, Japan is a coordinated market economy with participative labour relations, skill formation based on intensive training and a strong internal labour market (Olcott, 2009, p. 19). Moreover, Japan is repudiated for its "implicit code of restraint on the part of larger firms in the hiring of employees, particularly skilled ones, from other firms" (Olcott, 2009, p. 97).

In the sixth question, Czech managers tallied higher than their Japanese counterparts with 3.30 versus 2.87 , a difference of 0.43 . 
Based on this data, Czech managers have a stronger tendency to experiment with their supervisors' ideas and suggestions, even if not fully understood or make sense. This is consistent with the "Švejk" characteristic of Czech culture (Brunet-Thornton \& Bureš, 2012). This expression is often used to describe the adaptability and flexibility of the Czech business and cultural psyche.

The seventh question measures the pragmatic orientation of respondents in which Czech respondents indicate a stronger tendency towards long-term orientation. Question 8 measures the openness to adjust rules and improvise. Countries with high Uncertainty Avoidance scores exhibit a strong emotional need for rules and implement strong behavioural codes and laws (Hofstede, 2011, p. 10). The resulting difference in the responses is unexpected. The ninth presents a different perspective on a similar topic to that addressed by the previous question. Japanese managers stress the importance of "doing what is decided to be done", even if the individual reasons that modification of the rules benefits the company. Similarly, to the earlier, the results are comparable. The average values are higher for both that imply that both Czech and Japanese managers tend to disagree with this statement. Lastly question ten, which reveals that Japanese respondents show a slightly stronger tendency to improve gradually. Although the difference is 0.29 , the results correspond with Liker (2004), who stresses the importance of continuous improvement over a longer period of time.

\subsection{Conflict}

Japanese respondents perceive more conflicts with their Czech counterparts than the reverse. Japanese culture is highly-contextual. It is feasible that the frustration and complexity of Japanese-centric problems remain relatively unnoticed by their Czech colleagues. Another explanation is the concept of hansei or contemplation, the reflection-reviews introduced to TPS (Adler, Goldoftas, \& Levine, 1999). These reviews compel the employees to self-reflect on their approach to a process or an activity. In doing so, the member is encouraged to ponder over ways to improve in the future, both for their own benefit, and that of others.

Two insights can be concluded. Japanese managers resemble their Czech colleagues when estimating the degree of conflict between
Czech managers and operators. Secondly, the amount of conflict between Czech managers and manual workers is lower than that between Czech and Japanese management. It is not however as low as that between Czech managers as "individuals" and Japanese management.

Problem resolution with all group members is nemawashi, literally "going around the roots", as in "preparing the groundwork". This process creates mutual understanding thorough consideration in decision-making, or behindthe-scenes consensus (Kageyama, 2010). Typically, Czech managers tend to complete the task without consideration of long-term implication.

\section{Study Limitations and Further Research}

The utilisation of surveys to measure crosscultural values has its restrictions and limitations. Nasif, Al-Daeaj, Ebrahimi and Thibodeaux (1991) identifies seven problems with methodological research in cross-cultural studies that are applicable to this study as well: criterion problem as there does not exist an operational definition of culture; methodological simplicity as to ethnocentricity, functional equivalence and time frame; sampling issues as to the number of cultures included in a study or using a nation as a one study unit; instrumentation that involves translation, equivalence of variables and scales;, data collection elements that include research setting, timing equivalence, etc.; data analysis specifically, the use of qualitative versus quantitative data, simple statistical analyses and others and the level of analysis due to the confusion between country level with individual correlations.

In addition, there exits yet another wave of criticism directed towards Hofstede's research (Roberts \& Boyacigiller, 1984; McSweeney, 2002) focused on his methodological simplicity, sampling issues and level of analysis. Hofstede (2002) addresses these problems:

1. Surveys are not the most suitable method to measure cultural difficulties, but should not be the only source of information for cross-cultural studies;

2. Nations are currently the only units available to study cross-cultural differences;

3. Studying subsidiaries of one company might not provide information about the qualities of various cultures, but demonstrates clear differences between cultures; 
4. Data collected from Hofstede's studies are not new, but are based on values that have formed through many centuries, and therefore do not change quickly;

5. Five dimensions are not enough to comprehensively describe a culture, but meaningful to introduce other dimensions if they do not correlate with the existing ones.

When applied to this current work, the above defence is pertinent. The research uses quantitative data with its inherent risks and benefits, with descriptive statistics applied where appropriate. Within the risks related to qualitative analysis, it is crucial to understand that various Japanese subsidiaries in the Czech Republic hold different corporate values, education and training standards, and working relationships and structures between Czech and Japanese managers. The same applies to the background of the various employees. As only Japanese companies were polled, the amount of experience of each employee within the company impacts the results. Therefore, it is possible to mitigate this complication through the use of a sufficient dataset and a qualitative analysis of each company to account for the differences between each. Despite its qualitative nature, acquisition of a larger dataset enabling the application of sophisticated analytical techniques (e.g. MANOVA, or General Linear model) would be also fruitful.

The survey focuses on hidden values within a managerial system. Results suggest that these values are shared between the two cultures to a certain degree but that the application of the values creates issues. The extant literature emphasises the importance of clear TPS rules (Liker, 2004) but the actual application of these rules depend highly on actual situations. In this case, the values are prone to the specific circumstances and managerial priorities.

It is crucial to distinguish between correlation and causation. TPS training influences the values of the questionnaire respondents due to their positions held in the company. In addition, certain job functions are prone to higher degree of conflict or are subject to a lower level of employee satisfaction.

Differences in preference and approach together coupled with the perception of problem resolution reflect the Hall (1959) concept of high and low contextual cultures. The Toyota Production System was developed as a high- context system in a high-context society, and therefore members of the Czech society, a lowcontext culture, behave differently than system expectations.

\section{Conclusions}

The values measured in the survey and their subsequent results both confirmed expectations, and in some instances, produced unexpected conclusions. A predominant example of which is the value-based testing utilised for Hypothesis 1. From which, it is impossible to determine whether the values identified as inherent and native to TPS correspond to either Czech or Japanese cultures. Based on the applied methodology and its limitation, this study identifies the need for future research in the areas of TPS training standards in other countries, the involvement in other culturally based organisations, TPS deployment in nonJapanese companies and the like. Furthermore, both a quantitative survey-based analysis with a larger sample and a quantitative oriented case-study analysis within a smaller number of entities will clarify and further explore other issues identified in this study.

The support of the FIM UHK Excellence Project "MAS Applications in Modeling of Complex Socioeconomic Systems and Intelligent Environments" is gratefully acknowledged.

\section{References}

Adler, P.S., Goldoftas, B., \& Levine, D.I. (1999). Flexibility versus efficiency? A case study of model changeovers in the Toyota production system. Organisation Science, 10(1), 43-68. doi:10.1287/orsc.10.1.43.

Ayoko, O., Härtel, C., \& Callan, V. (2002). Resolving the puzzle of productive and destructive conflict in culturally heterogeneous workgroups: A communication accommodation theory approach. International Journal of Conflict Management, 13(2), 165-195. doi:10.1108/eb022873.

Bergiel, E., Bergiel, B., \& Upson, J. (2012). Revisiting Hofstede's Dimensions: Examining the Cultural Convergence of the United States and Japan. American Journal of Management, 12(1), 69-79.

Brunet-Thornton, R., \& Bureš, V. (2012). Cross-cultural Management: Establishing a Czech Benchmark. E\&M Ekonomie a Management, 15(3), 46-62. 
Cardon, P.W., \& Marshall, B.A. (2008). National culture and technology acceptance: The impact of uncertainty avoidance. Issues in Information Systems, 9(2), 103-110.

Clark, T., \& Pugh, D.S. (2001). Foreign country priorities in the internationalization process: a measure and an exploratory test on British firms. International Business Review, 10(3), 285-303. doi:10.1016/S09695931(01)00017-8.

Delios, A, \& Bjorkman, I. (2000). Expatriate staffing in foreign subsidiaries of Japanese multinational corporations in the PRC and the United States. The International Journal of Human Resource Management, 11(2), 278-293. doi:10.1080/095851900339873.

Friborg, O., Martinussen, M., \& Rosenvinge, J. (2006). Likert-based vs. semantic differentialbased scorings of positive psychological constructs: A psychometric comparison of two versions of a scale measuring resilience. Personality and Individual Differences, 40(5), 873-884. doi:10.1016/j.paid.2005.08.015.

Fujimoto, T. (1999). The evolution of a manufacturing system at Toyota. New York: Oxford University Press.

Fukuda, J. (2012). The Effects of Working Hours Schemes on Overtime Working Hours in Japan. Evolutionary and Institutional Economic Review, 9(1), 169-181. doi:10.14441/eier.A2012007.

Gerschewski, S. (2013). Improving on the Kogut and Singh metric of psychic distance. Multinational Business Review, 21(3), 257-268. doi:10.1108/MBR-04-2013-0019.

Gómez-Mejia, L., \& Palich, L. (1997). Cultural Diversity and the Performance of Multinational Firms. Journal of International Business Studies, 28(2), 309-335.

Hall, E. (1959). The silent language. Garden City, NY: Doubleday.

Hampden-Turner, C., \& Trompennars, F. (1998). Riding The Waves of Culture: Understanding Diversity in Global Business. New York: McGraw-Hill.

Harzing, A. (1999). Managing the multinationals. Cheltenham, UK: E. Elgar.

Harzing, A. (2014). Resources in International \& Cross-cultural Management, Research Quality and Impact. Retrieved December 15, 2015, from http://www.harzing.com/resources.htm.

Harzing, A.W., \& Pudelko, M. (2013). Language competencies, policies and practices in multinational corporations: A comprehensive review and comparison of Anglophone, Asian,
Continental European and Nordic MNCs. Journal of World Business, 48(1), 87-97. doi:10.1016/j.jwb.2012.06.011.

Hofstede, G. (1983). The Cultural Relativity of Organisational Practices and Theories. Journal of International Business Studies, 14(2), 75-89.

Hofstede, G. (2002). Dimensions Do Not Exist: A Reply to Brendan McSweeney. Human Relations, 55(11), 1355-1361. doi:10.1177/00187267025511004.

Hofstede, G. (2011). Dimensionalizing Cultures: The Hofstede Model in Context. Online Readings in Psychology and Culture, 2(1). doi:10.9707/2307-0919.1014.

Holtbrügge, D., \& Berg, N. (2004). Knowledge transfer in multinational corporations: evidence from German firms. Management International Review, 44(3), 129-146. doi:10.1007/978-3-322-91001-1_7.

Jayamaha, N., Wagner, J., Grigg, N., Campbell-Allen, N., \& Harvie, W. (2014). Testing a theoretical model underlying the 'Toyota Way'An empirical study involving a large global sample of Toyota facilities. International Journal of Production Research, 52(14), 4332-4350. doi:10.1080/00207543.2014.883467.

Kageyama, Y. (2010, February 25). The quiet leader: Japanese culture creates a different kind of leader. Daily Herald.

Kohun, F., Burčik, V., \& Skovira, R.J. (2012). Research into Hofstede's Thesis. In Knowledge and Learning: Global Empowerment. Proceedings of the Management, Knowledge and Learning International Conference (pp. 989-997). Celje, Slovenia.

Kogut, B., \& Singh, H. (1988). The effect of national culture on the choice of entry mode. Journal of International Business Studies, 19(3), 411-432.

Li, X., Roberts, J., Yan, Y., \& Tan, H. (2016). Management of cultural differences under various forms of China-UK higher education strategic alliances. Studies in Higher Education, 41(4), 774-798. doi:10.1080/03075079.2014.966664.

Liker, J., Fruin, W., \& Adler, P. (1999). Remade in America. New York: Oxford University Press.

Liker, J. (2004). The Toyota way. New York: McGraw-Hill.

Lincoln, J., Kerbo, H., \& Wittenhagen, E. (1995). Japanese Companies in Germany: A Case Study in Cross-Cultural Management. Industrial Relations, 34(3), 417-440. 
Linder, C. (2015). Expatriates' willingness to adjust their symbolic leadership abroad: An analysis of how culture affects expatriates' use of symbolic interaction. Journal of Global Mobility, 3(3), 244-272. doi:10.1108/JGM-052014-0013.

Manev, I., \& Stevenson, W. (2001). Nationality, Cultural Distance, and Expatriate Status: Effects on the Managerial Network in a Multinational Enterprise. Journal of International Business Studies, 32(2), 285-303. doi:10.1057/palgrave.jibs.8490953.

Marsden, D. (1999). A theory of employment systems. Oxford: Oxford University Press.

McSweeney, B. (2002). Hofstede's Model of National Cultural Differences and their Consequences: A Triumph of Faith - a Failure of Analysis. Human Relations, 55(1), 89-118. doi:10.1177/0018726702551004.

Monden, Y. (2013). Management of service businesses in Japan. Singapore: World Scientific.

Nasif, E.G., Al-Daeaj, H., Ebrahimi, B., \& Thibodeaux, M.S. (1991). Methodological problems in cross-cultural research: an updated review. MIR: Management International Review, 31(1), 79-91.

OECD (2014). Hours worked (indicator). OECDiLibrary. Retrieved November 27, 2015, from http://www.oecd-ilibrary.org/employment/ hours-worked/indicator/english_47be1c78-en. doi:10.1787/47be1c78-en.

Olcott, G. (2009). Conflict and change. Cambridge, UK: Cambridge University Press.

Pudelko, M. (2000). Das Personalmanagement in Deutschland, den USA und Japan. Volumes 1-3. Cologne: Saborowski.

Pudelko, M., \& Tenzer, H. (2011). Conflict in foreign subsidiaries of Japanese and western multinational corporations: The impact of cultural distance and differences in homehost country combinations. Zeitschrift Fur Betriebswirtschaft, 81(3), 49-71. doi:10.1007/ s11573-011-0456-9.

Roberts, K.H., \& Boyacigiller, N.A. (1984). Cross-national organisational research: The grasp of the blind men. In B.L. Staw, \& L.L. Cummings (Eds.), Research on organisational behaviour (pp. 423-475). Greenwich, CT: JAI Press.

Rozkwitalska, M. (2010). Barriers of Crosscultural Interactions According to the Research
Findings. Journal of Intercultural Management, 2(2), 37-52.

Schein, E.H. (1985). Organisational Culture and Leadership. San Francisco: Jossey-Bass.

Shenkar, O. (2012). Cultural distance revisited: Towards a more rigorous conceptualization and measurement of cultural differences. Journal of International Business Studies, 43(1), 1-11. doi:10.1057/jibs.2011.40.

Spear, S., \& Bowen, H. (1999). Decoding the DNA of the Toyota production system. Harvard Business Review, 77(SeptemberOctober), 96-108.

Toyota. (2003). The Environmental and Social Report 2003. Retrieved December 9, 2015, from http://www.toyota. co.jp/en/environmental_rep/03/pdf/E_ kankyouohoukoku2003.pdf.

Vaara, E. (2003). Post-acquisition Integration as Sensemaking: Glimpses of Ambiguity, Confusion, Hypocrisy, and Politicization. Journal of Management Studies, 40(4), 859-894. doi:10.1111/1467-6486.00363.

Wong, M., \& Hendry, C. (1999). Employment strategy: Comparing Japanese and British retail companies in Hong Kong. Personnel Review, 28(5/6), 474-490. doi:10.1108/00483489910286783.

Yeganeh, H. (2011). A generic conceptualization of the cultural distance index: Application to Schwartz's and Hofstede's frameworks. Journal of Strategy and Management, 4(4), 325-346. doi:10.1108/17554251111180990.

Richard Brunet-Thornton, FRSA, MIM, MBA, PhD University of Economics Prague Faculty of Business Administration Cross-Cultural Management Centre richard.brunet-thornton@vse.cz

Mgr. Bc. Michal Koža, MıM Arthur D. Little GmbH michal.koza@adlittle.com

doc. Ing. Vladimír Bureš, MBA, Ph.D. University of Hradec Králové Faculty of Informatics and Management vladimir.bures@uhk.cz 


\begin{tabular}{|c|c|}
\hline Appendix 1: & urvey questions / statements \\
\hline Section & Questions / Statements \\
\hline $\begin{array}{l}\text { Basic } \\
\text { information }\end{array}$ & $\begin{array}{l}\text { Your nationality: } \\
\text { Your age: } \\
\text { Your position in the company: } \\
\text { Name of the company: } \\
\text { How long do you work in the current company: }\end{array}$ \\
\hline Personal views & $\begin{array}{l}\text { In order to be competitive, it is better to stick with current technology because it is } \\
\text { proven } \\
\text { If a solution doesn't solve a problem, it is important to try something else because } \\
\text { it might be a wrong solution } \\
\text { If the supervisors' requests are not clear, it is my fault because I do not understand } \\
\text { them enough } \\
\text { In determining how to achieve goals, employees should have a certain degree of } \\
\text { freedom } \\
\text { It is more efficient to hire a manager from external sources who knows "new } \\
\text { approaches" } \\
\text { If supervisor's ideas don't make sense, subordinates should at least try them out } \\
\text { Persistent effort is the best way to achieve results } \\
\text { In real life circumstances, the occasional adjustment of rules to overcome } \\
\text { problems is unavoidable } \\
\text { A company's rules should not be broken, even when the employee thinks breaking } \\
\text { the rule would be in the company's best interest. } \\
\text { It is more efficient to improve things radically, than to improve them gradually over } \\
\text { time (with the same outcome). }\end{array}$ \\
\hline Job satisfaction & $\begin{array}{l}\text { Number of hours spent working } \\
\text { Wage (monetary reward) } \\
\text { Training and education } \\
\text { Overall satisfaction }\end{array}$ \\
\hline Conflicts & $\begin{array}{l}\text { There exist many conflicts between you and management of other than your own } \\
\text { nation. } \\
\text { There exist many conflicts between Japanese management and Czech } \\
\text { management. } \\
\text { There exist many conflicts between Japanese management and Czech operators. } \\
\text { There exist many conflicts between Czech management and Czech operators. } \\
\text { It is more effective to solve work-related problems without the presence of } \\
\text { managers from another nationality }\end{array}$ \\
\hline Experience & $\begin{array}{l}\text { Have you worked for a Japanese company before? } \\
\text { Have you taken a cross-cultural skills seminar, course or presentation? } \\
\text { Have you taken an official Toyota Production System seminar, course or } \\
\text { presentation? } \\
\text { Have you obtained unofficial Toyota Production System education? (on-the-job } \\
\text { training, discussions with colleagues, short presentations etc.) }\end{array}$ \\
\hline
\end{tabular}




\title{
Abstract
}

\section{THE TOYOTA PRODUCTION SYSTEM - CZECH AND NIPPON CULTURAL PERSPECTIVES}

\author{
Richard Brunet-Thornton, Michal Koža, Vladimír Bureš
}

This text focuses on the cultural relationships between Czech nationals employed at Japanese subsidiaries located in the Czech Republic. The paper analyses the possibilities of implementation of Toyota Production System within Japanese subsidiaries in Czech Republic. Moreover, it explores both the fit between the cultural values of Czech and Japanese management and the values incorporated in the Toyota Production System, and the various relationships of employees of both cultures at a managerial and operational level. In order to conduct the study, 79 companies were contacted, and survey responses from a total of 108 Czech and Japanese employees were collected. Using a self-administered questionnaire created in Czech, English and Japanese language, the findings of both common and divergent culturally-induced perspectives are analysed. Due to consistency with other cross-cultural studies Hofstede's cultural dimensions are used as foundation. The discussion correlates the results to the extent that they are deemed appropriate. Hall's low and high context models supplement the discussion, where applicable, to further explain issues relative to perception and communication. The dialogue is rich in the knowledge of Japanese methodologies of quality and overall management practice known in this case as the Toyota Production System. Data from the survey show that both Czech and Japanese employees have similar values related to work and neither job satisfaction nor number of conflicts is connected with TPS training. The manuscript concludes with both the list of existing research limitations that can be overcome in next studies, and an analysis of the need for further research within other crosscultural frameworks.

Key Words: Cross-Cultural Management, Toyota Production System, Czech Republic.

JEL Classification: M14, M16, F23, O15.

DOI: $10.15240 / t u l / 001 / 2016-2-010$ 